See Article page XXX.

\section{Commentary: The hardest part of cardiothoracic surgery is getting to do it}

\author{
Michael Ma, MD
}

In the most in-depth, quantitative analysis of the integrated thoracic surgery match published to date, Bougioukas and colleagues ${ }^{1}$ provide some concise answers for applicants and faculty by studying aggregated data from the Association of American Medical Colleges, the Electronic Residency Application Service, and the National Residency Matching Program.

As an applicant, what are your chances of matching in thoracic surgery from medical school? In comparison to other surgical subspecialties (eg, neurosurgery, otolaryngology, plastics, orthopedics, and vascular), applicants who matched in thoracic surgery during 2019-2020 ranked highest in percentage from top-40 National Institutes of Health-funded medical schools (54.5\%), Alpha Omega Alpha national medical honor society members $(48.5 \%)$, and US Medical Licensing Exam Step 2 Clinical Knowledge score (255.1). In other metrics, including US Medical Licensing Exam Step 1 score (247.5), number of research experiences (4.8), number of abstracts/presentations/publications (14.5), entering residents also appeared very competitive. This cohort applied to a greater number of specialties (2.1) and to the vast majority of accredited programs $(79.3 \%)$ within thoracic surgery.

As faculty, how are we engaging the future of our specialty? Clearly, overall demand to train in thoracic surgery is outpacing its supply. Year after year in the past decade,

\footnotetext{
From the Department of Cardiothoracic Surgery, Stanford University School of Medicine, Stanford, Calif.

Disclosures: The author reported no conflicts of interest.

The Journal policy requires editors and reviewers to disclose conflicts of interest and to decline handling or reviewing manuscripts for which they may have a conflict of interest. The editors and reviewers of this article have no conflicts of interest.

Received for publication Dec 22, 2021; revisions received Dec 22, 2021; accepted for publication Dec 22, 2021.

Address for reprints: Michael Ma, MD, Department of Cardiothoracic Surgery, Falk Cardiovascular Research Center, Stanford University School of Medicine, 300 Pasteur Dr, Stanford, CA 94035 (E-mail: mma@stanford.edu).

J Thorac Cardiovasc Surg 2022; $\mathbf{\square}: 1-2$

$0022-5223 / \$ 36.00$

Copyright (C) 2021 by The American Association for Thoracic Surgery

https://doi.org/10.1016/j.jtcvs.2021.12.040
}

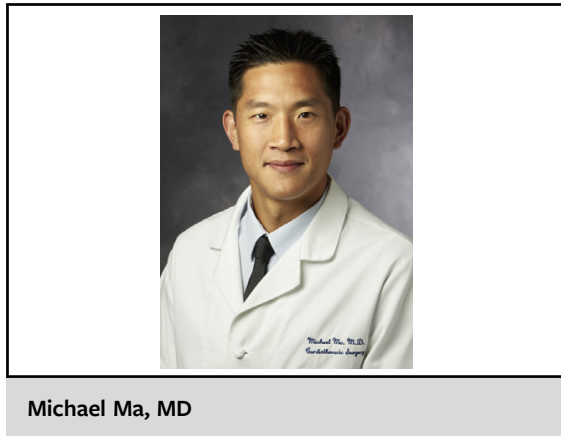

CENTRAL MESSAGE

Applicants to our specialty are extremely gifted. Opportunities to enable their collective talents must be created, with a greater focus on access for all.

there have been far fewer positions than applicants, with a peak number of applicants per position (7.3 in 2010) settling over the second half of the decade (3.16 in 2020). Program and position growth occurred simultaneously, and have also plateaued, with 38 positions currently distributed across 29 programs. The match rate in thoracic surgery is significantly lower than the other included subspecialties, most recently at $31.7 \%$. With respect to diversity, equity, and inclusion, modest gains have been accrued over the study period, although in both absolute terms and relative to other subspecialties, our efforts remain quite average. The number of female applicants has risen from $16 \%$ to $28 \%$ during the study period. The number of Black, Asian, and Hispanic applicants has each risen by $1 \%$ to $2 \%$ in that interval.

How do we best use this information? Cautiously as an applicant, and motivationally as faculty. The various data sources utilized in this analysis capture a mixture of results sourced from a single year (2019-2020) with trends established over a decade (2010-2020) of observation. Applicant competitiveness is derived from a cohort of presumably 39 or fewer individuals in the last match year, and high performance along a variety of measurable standards only captures the immediately quantifiable aspects of a successful application that will include strong letters of reference, subinternship rotations, interviews, and other less-tangible considerations. Scarcity of access, for all interested students and more strikingly amongst women and racial minorities, 
remains pronounced, and should inspire our continued efforts to improve education for our next, highly gifted, generation.

\section{Reference}

1. Bougioukas L, Heiser A, Berg A, Polomsky M, Rokkas C, Hirashima F. Integrated cardiothoracic surgery match: trends among applicants when compared with other surgical subspecialties. J Thorac Cardiovasc Surg. 2022. XXX:XXX. 